\title{
FLUID LOSS IN RATS WITH TOURNIQUET SHOCK ${ }^{1}$
}

\author{
By SIMON KOLETSKY AND GORDON E. GUSTAFSON \\ (From the Institute of Pathology and Department of Biochemistry, Western Reserve University \\ School of Medicine, Cleveland)
}

(Received for publication April 24, 1946)

Release of a high unilateral tourniquet producing complete interruption of blood flow to a hind limb of the rat for about 5 hours almost invariably results in fatal shock. The development of shock is accompanied by progressive edema of the limb. The main object of the following experiments was to determine the magnitude and the rapidity of the fluid loss in the injured extremity.

\section{METHODS}

Adult white male rats weighing about 150 to 300 grams were used. These were anesthetized with sodium pentobarbital, given intraperitoneally in dosage of 25 to $35 \mathrm{mgm}$. per $\mathrm{kgm}$. of body weight $(0.3$ to $0.4 \mathrm{ml}$. of a 2 per cent solution). Circulation in the left lower extremity was then entirely occluded by 2 tightly wound rubber band tourniquets. The first was placed around the knee in order to obtain extension of the leg. This facilitated the application of the second tourniquet, which was placed as high as possible in the groin, anchorage being obtained over a redundant segment of skin drawn down beneath the rubber band.

Constriction was maintained for 5 hours and $10 \mathrm{~min}$ utes, at the end of which time the rats were alert and showed complete outward recovery from the anesthesia. The animals were then sacrificed by decapitation, either without release of tourniquet, or at fixed time intervals after release, i.e., 15 minutes, 30 minutes, and 1, 2 and 3 hours. The experiments were performed with small groups of rats sacrificed at different periods by random selection, until there was a total of 20 rats for each time interval.

In each group there were 1 or more control rats which developed shock after removal of tourniquet and went on to death. Since these yielded only little blood at the time of death, an additional group of 11 rats was sacrificed at 5 to 6 hours following removal of constriction, in order to obtain sufficient blood for chemical determinations. In 18 rats sacrificed by ether at various intervals after tourniquet release, the figures for fluid loss were of the same order as those obtained from decapitated animals.

There were a few deaths apparently due to anesthesia. In addition, several rats which chewed their leg before or after removal of tourniquet were discarded. Food and water were withheld for a period of about 10 hours be-

1 Aided by a grant from the Elisabeth Severance Prentiss Foundation. fore anesthesia was given, and also during the course of the experiments. The latter were performed at room temperature during the summer and autumn seasons.

The amount of fluid lost in the leg following removal of tourniquet was determined by the method of bisection $(1,2)$. An anterior midline incision was made from sternum to symphysis pubis and followed by evisceration. A similar posterior midline incision extended down across the base of the tail. The spine was then transected at about the level of the first or second lumbar vertebra, and the lower extremities separated by bilateral paravertebral incisions passing through the hip joints.

The difference in weight between the normal and the edematous extremity gave the gain in weight of the latter due to accumulation of fluid. For convenience, this increase was expressed in terms of percentage of total body weight.

In addition to local fluid loss, other items studied were: (1) hemoconcentration, (2) total protein of edema fluid and blood serum, and (3) blood serum creatine.

Hemoconcentration was measured by hematocrit (3) with powdered heparin as anticoagulant. Control values were obtained on all rats prior to application of tourniquet, and again at the time of sacrifice. This afforded a comparison between progressive loss of fluid and hemoconcentration.

Total protein was determined by the falling drop method (4). Edema fluid was secured from the legs of rats sacrificed at 2,.3 and 5 to 6 hour intervals following release of the tourniquet. Incisions of skin, subcutaneous tissue and fascial planes were made, and pale pink fluid obtained on the surface of a scalpel blade by gentle pressure. This was transferred to a small dish containing powdered heparin to prevent clotting. Incision of muscle was avoided in order to prevent contamination with blood.

Creatine was determined as follows: a Folin-Wu filtrate was acidified to a final concentration of $1 \mathrm{~N} \mathrm{HCl}$, and then autoclaved at 15 pounds pressure for 20 minutes. After cooling, an amount of $\mathrm{NaOH}$ equivalent to the $\mathrm{HCl}$ was added. The remainder of the procedure was the same as for creatinine (5), the creatine level being obtained by the difference in the 2 values.

Autopsies were performed on most rats, and sections obtained from various organs for microscopic study.

\section{RESULTS}

Control rats. There were 15 control rats, all of which died in shock following removal of the tourniquet. The period of survival ranged from 2 to 
23 hours, with an average of $71 / 2$ hours. Bisection of 9 animals gave a mean increase in weight of the injured leg equal to 4.8 per cent of body weight, and a range of 4.3 to 5.7 per cent. Hemoconcentration was marked at the time of death, the mean levels of the normal and experimental hematocrits being 48.7 and 77.8 respectively. The normal hematocrits ranged from 46.0 to 52.5 , and the experimental from 72.5 to 82.5 .

TABLE I

Fluid loss

\begin{tabular}{l|c|c}
\hline \hline \multirow{2}{*}{$\begin{array}{c}\text { Time of sacrifice after } \\
\text { release of tourniquet* }\end{array}$} & \multicolumn{2}{|c}{ Percentage of body weight } \\
\cline { 2 - 3 } & Mean & Range \\
\hline Nonet & 1.1 & 0.8 to 1.4 \\
15 minutes & 2.1 & 1.6 to 2.6 \\
30 minutes & 2.8 & 2.3 to 3.5 \\
1 hour & 3.4 & 3.0 to 4.1 \\
2 hours & 4.2 & 3.4 to 4.7 \\
3 hours & 4.8 & 4.0 to 6.2 \\
\hline
\end{tabular}

* 20 rats were sacrificed at each time interval.

$\dagger$ Rats sacrificed after 5 hours and 10 minutes without release of tourniquet.

Local fluid loss. Table I shows the amount of fluid, expressed as percentage of total body weight, lost into the extremity before and at various time intervals after release of tourniquet. The rate of extravasation is indicated by the graph in Figure 1.

In rats sacrificed after a 5-hour and 10-minute

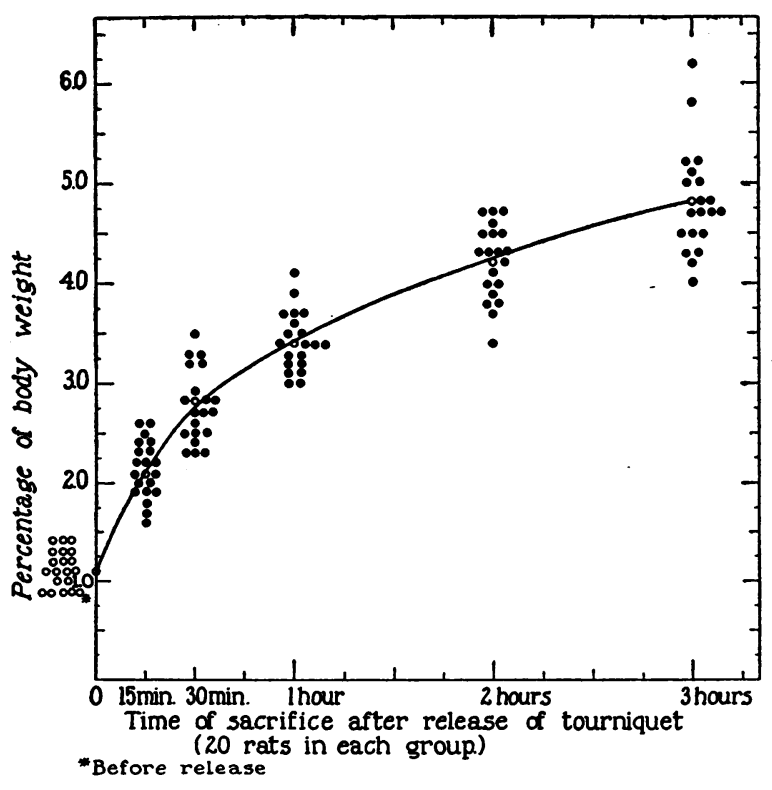

Fig. 1. Mean Fluid Loss period of constriction with the rubber bands still in place, the extremity showed a mean increase in weight equal to 1.1 per cent of body weight. Presumably this was due to blood trapped in the leg by the tourniquet, and also to the development of edema proximal to the rubber band. Fifteen minutes after removal of the tourniquet, the mean fluid loss amounted to 2.1 per cent of body weight, rose to 2.8 per cent at 30 minutes, and then to 3.4 , 4.2 and 4.8 per cent at 1,2 and 3 hours respectively. Thus, there was rapid loss of fluid in the first 15 minutes following release of tourniquet, a slightly reduced but still rapid extravasation during the next 15 minutes, and thereafter a distinct and progressive diminution in the rate of loss. The increments in leg weight per 15 minutes following tourniquet removal were 1 per cent of body weight in the first 15 minutes, 0.7 per cent in the following 15 minutes, 0.3 per cent in the next $1 / 2$ hour, 0.2 per cent during the second hour, and 0.15 per cent during the third hour.

TABLE II

Hemoconcentration

\begin{tabular}{l|c|c|c|c|c}
\hline \hline & \multicolumn{2}{|c|}{$\begin{array}{c}\text { Normal } \\
\text { Time of sacrifice } \\
\text { after release of } \\
\text { tourniquet }\end{array}$} & \multicolumn{2}{|c|}{$\begin{array}{c}\text { Experimental } \\
\text { hematocrit }\end{array}$} & $\begin{array}{c}\text { Increase } \\
\text { in hem- } \\
\text { atocrit }\end{array}$ \\
\cline { 2 - 5 } & Mean & Range & Mean & Range & \\
\hline None & 47.8 & 42 to 52 & 49.0 & 46 to 57 & 1.2 \\
15 minutes & 46.9 & 43 to 50 & 56.6 & 54 to 60 & 9.7 \\
30 minutes & 46.7 & 44 to 50 & 58.6 & 53 to 66 & 11.9 \\
1 hour & 47.5 & 43 to 51 & 61.7 & 59 to 68 & 14.2 \\
2 hours & 46.6 & 36 to 51 & 65.1 & 58 to 71 & 18.5 \\
3 hours & 47.9 & 45 to 51 & 71.3 & 62 to 83 & 23.4 \\
\hline
\end{tabular}

Hemoconcentration. The mean values and the range of experimental and normal hematocrits are given in Table II. In rats sacrificed after 5 hours and 10 minutes of constriction without removal of the tourniquet, the change in hematocrit was variable, i.e., either a slight rise or fall, or practically no change. Although bisection of the 20 rats sacrificed at this time revealed an average increase in weight of the injured leg equal to $1.1 \mathrm{per}$ cent of body weight, there was an average increase of only 1.2 in hematocrit. After removal of the tourniquet the hematocrit rose sharply, and at the end of 15 minutes there was a mean increase of 9.7 over the normal. At the end of 30 minutes the mean increase was 11.9 , and thereafter the values rose to $14.2,18.5$, and 23.4 at 1,2 and 3 hours respectively. 
The greatest increment in hematocrit occurred in the first $1 / 4$ hour after removal of tourniquet, corresponding to the period of most rapid fluid loss into the extremity. The increment was considerably reduced during the next 15 minutes, even though local fluid loss was still rapid. In the following $2 \frac{1}{2}$ hours, as fluid loss diminished progressively, the hematocrit continued to rise slowly, and after the first hour at the approximate rate of 1 unit per 15 minutes.

Total protein of edema fluid and blood serum. The protein content of the edema fluid in the injured leg was determined in 37 rats. This fluid was obtained from animals sacrificed at 2, 3 and 5 to 6 hours after release of tourniquet, and the mean values at these periods were 6.1, 5.7, and 5.4 grams per $100 \mathrm{ml}$. respectively. Such levels amounted to approximately 68 to 80 per cent of the corresponding values for serum protein (Table III). The figures for the latter did not differ

TABLE III

Total protein of edema fluid

\begin{tabular}{l|c|c|c|c|c}
\hline \hline $\begin{array}{c}\text { Time of sacrifice } \\
\text { after release of } \\
\text { tourniquet }\end{array}$ & $\begin{array}{c}\text { Number } \\
\text { of rats } \\
\text { with de- } \\
\text { termina- } \\
\text { tions }\end{array}$ & Mean & Range & Mean & Range \\
\hline 2 hours & 8 & 6.1 & 5.2 to 6.9 & 7.6 & 7.2 to 7.8 \\
3 hours & 18 & 5.7 & 4.7 to 6.5 & 7.1 & $\begin{array}{c}\text { Corresponding } \\
\text { serum protein }\end{array}$ \\
5 to 6 hours & 11 & 5.4 & 4.9 to 6.5 & 8.0 & 7.6 to 8.3 \\
\hline
\end{tabular}

appreciably at any of the time intervals after tourniquet removal, and were also within the range of determinations on 10 normal rats which averaged 7.4 grams, and varied from 7.0 to 7.8 grams (Table IV). Thus progressive fluid loss and hemoconcentration were not accompanied by a significant rise or fall in serum protein.

TABLE IV

Total serum protein

\begin{tabular}{c|c|c|c|c}
\hline & $\begin{array}{c}\text { Number of } \\
\text { Time of sacrifice after } \\
\text { release of tourniquet } \\
\text { rats with } \\
\text { determina- } \\
\text { tions }\end{array}$ & \multicolumn{2}{|c}{ Grams per $100 \mathrm{ml}}$. \\
\cline { 2 - 4 } None & 19 & 7.8 & 5.9 to 9.3 \\
15 minutes & 19 & 8.0 & 6.2 to 10.2 \\
30 minutes & 13 & 7.9 & 6.6 to 10.0 \\
1 hour & 13 & 8.0 & 6.4 to 11.4 \\
2 hours & 8 & 7.3 & 5.9 to 8.4 \\
3 hours & 5 & 7.1 & 6.7 to 7.8 \\
\hline
\end{tabular}

Serum creatine. Determinations of serum creatine in 10 normal rats gave a mean level of 12.9 mgm. per $100 \mathrm{ml}$., and a range of 9.0 to 15.9 . In rats sacrificed after 5 hours and 10 minutes of constriction of a hind limb with tourniquet still in place, there was no significant change in this value, i.e., in 19 rats the mean level was 10.9 mgm., and the range 8.7 to 13.1 . However, following release of the tourniquet there was a rapid and steady rise in serum creatine (Table V). This amounted to

TABLE V

Serum creatine

\begin{tabular}{c|c|c|c}
\hline \hline \multirow{2}{*}{$\begin{array}{c}\text { Time of sacrifice after } \\
\text { release of tourniquet }\end{array}$} & $\begin{array}{c}\text { Number of } \\
\text { determina- } \\
\text { tions }\end{array}$ & \multicolumn{2}{|c}{ Mgm. per $100 \mathrm{ml}}$. \\
\cline { 3 - 4 } & 19 & Mean & \multicolumn{2}{|c}{ Range } \\
\hline None & 19 & 20.1 & 8.7 to 13.1 \\
15 minutes & 13 & 27.4 & 15.9 to 24.7 \\
30 minutes & 13 & 29.4 & 23.6 to 38.3 \\
1 hour & $7^{*}$ & 35.1 & 24.4 to 40.0 \\
2 hours & $5^{*}$ & 40.2 & 37.6 to 43.8 \\
3 hours & $3^{*}$ & 64.5 & 59.2 to 68.9 \\
5 to 6 hours & &
\end{tabular}

* Determinations made on pooled blood, usually from 2 or 3 rats.

an increase over the normal of approximately 100 per cent at the end of $1 / 2$ hour, 200 per cent at the end of 3 hours, and 400 per cent between 5 and 6 hours. Again, the increment was largest in the first 2 fifteen-minute periods following removal of the tourniquet, after which a progressive rise was maintained at a slower rate during the next 5 hours.

Serum creatinine was slightly elevated during the course of the experiments, probably as a result of renal failure. From a mean level on 10 normal rats of $1.4 \mathrm{mgm}$. per $100 \mathrm{ml}$., the mean values rose to 2.8 and $3.2 \mathrm{mgm}$., 1 and 2 hours respectively after tourniquet release.

\section{DISCUSSION}

A high unilateral tourniquet applied to the hind limb of a rat, maintained for about 5 hours and then released, leads to the production of shock which, without therapy, is almost constantly fatal. Of 75 such experimental rats, 73 died within 24 hours, a mortality of 92 per cent. The time of survival after release of tourniquet ranged from 2 to 23 hours, and averaged 7 hours. In 65 rats the amount of fluid lost into the injured extremity 
at the time of death varied from 3.2 to 7 per cent, and the mean loss was 5 per cent.

Although blood pressures were not recorded in this study, the course of events prior to death was typical of shock. Within 1 or 2 hours after removal of tourniquet the animals usually began to show apathy, weakness and neuromuscular depression. These were progressive, and were followed by pallor and lividity of paws, prostration and respiratory distress, which became marked shortly before death.

Edema. The quantity of edema fluid in the injured extremity was determined by bisection of the animal, utilizing the technique of Blalock (1) modified by Hechter, Krohn and Harris (2). Gain in weight of injured over normal leg gave the amount of extravasated fluid. The method was used originally by Cannon and Bayliss (6) who severed injured and normal extremities across the upper thigh. Parsons and Phemister (7) compared the weights of the lower extremities, after symmetrical amputation along the lines of attachment to the innominate bones. Blalock's modification was designed to include groin, pelvis and flank on each side, since edema occurs in these regions as well as in leg proper. This undoubtedly gave a more accurate estimate of the quantity of extravasated fluid.

Bisection can be performed with a fairly high degree of accuracy. Cullen and Freeman (8) separated the extremities of 15 normal dogs and obtained an average difference in weight amounting to 0.32 per cent of body weight. In 12 normal rats we obtained an average error of only 0.18 per cent of body weight.

Moon's objection (9) to the use of bisection is based on the fact that as fluid escapes into the affected side, a simultaneous absorption occurs from the tissues of the normal side, thereby decreasing its weight. Since the difference in weight of the extremities includes twice the volume of the fluid shifted, i.e., volume gained in one leg and lost from the other, he claims that the error of the method is doubled. Although this criticism is valid, the estimated error is too large. The extravasated fluid comes from the rest of the body as well as from the normal extremity, the latter probably contributing an amount roughly proportional to its weight. On this basis, the figures for fluid loss obtained by bisection are about 10 per cent higher than the actual values.

In our study, rats with unilateral tourniquet shock showed a mean fluid loss of 5 per cent of body weight at the time of death, which averaged 7 hours after removal of tourniquet. Similar figures have been obtained for dogs in both tourniquet and traumatic shock by other investigators who also used the method of bisection. In Blalock's animals, fluid loss at death ranged from 4.1 to 5.1 per cent of body weight (1). Parsons and Phemister's values were approximately in the same range (7), while Holt and MacDonald (10) reported fluid loss slightly in excess of 4 per cent of body weight. In 13 dogs dead of tourniquet shock, Wilson and Roome (11) stated that the average increase in weight of the injured leg was 3.54 per cent of body weight. Ashworth, Jester and Guy (12) reported a value of about 4 per cent in shock produced by a combination of tourniquet and trauma. Perlow and co-workers (13) found a fluid loss of 4 to 6.1 per cent of body weight in dogs following occlusion of the veins to one hind extremity. Using a similar technique, Schlesser and Asher (14) obtained figures ranging from 3 to 8 per cent of body weight.

Fluid loss in shock has also been determined by the method of immersion (15 to 17). Swelling of the limb is obtained from the volume of fluid displaced before and after injury, and at death. This procedure fails to include edema fluid which collects in soft tissues, especially pelvis and flank, without causing expansion and hence gives values lower than those obtained with bisection. A comparison of the 2 methods in dogs by Green and associates (16) showed that the gain in volume measured by immersion ranged from 63 to 88 per cent of the difference in weight of the 2 extremities.

Nickerson (17) inserted dogs into a specially constructed tank and measured gain in volume of the traumatized extremity by the amount of water drained from the tank. He reported that in fatal cases the average swelling just after trauma was 4.1 per cent, and at death 4.8 per cent, of body weight.

The rats in this study showed reactive hyperemia of the constricted leg almost immediately after renewal of blood flow. Edema also appeared 
promptly, and was often detected grossly in the paw within a few minutes. The entire leg then underwent marked swelling, and progressive increase in size was visible for about 1 hour following restoration of the circulation. It was plainly evident that a large quantity of fluid was lost rapidly into the tissues of the limb.

At first, the edema fluid collected principally in the leg below the site of constriction, and when further expansion here was prevented by tissue tension, there was overflow into the lower abdominal wall and flank. The fluid gravitated into the fascial plane between subcutaneous tissue and oblique abdominal muscles. As shown by the curve in Figure 1, fluid loss was very rapid during the first $1 / 2$ hour after tourniquet removal, diminished during the next $1 / 2$ hour, and then leveled off distinctly thereafter. The mean loss amounted to $2.8,3.4,4.2$ and 4.8 per cent of total body weight, 30 minutes, 1 hour, 2 hours and 3 hours respectively after the tourniquet was released. Haist and Hamilton (18) obtained a similar curve in rats based on increase in volume of the hind limbs following release of constricting clamps. The progressive reduction in fluid loss is what might be expected in tourniquet shock, because of the limiting factors of falling blood pressure, increasing tissue tension, and high osmotic pressure of the extravasated fluid.

The extravasation of fluid is due to capillary injury resulting from the long period of total ischemia. Complete and prolonged anoxemia causes marked increase in capillary permeability $(19,20)$. Presumably this is brought about by the action of chemical substances liberated locally by tissue breakdown. Holt and MacDonald (10) state that there is no evidence that such substances enter the systemic circulation.

The edema fluid was usually pale pink, slightly viscid, and resembled plasma. Hemorrhage was minimal or negligible, as shown by gross and microscopic study. In this respect, tourniquet shock differs from traumatic shock in which there is usually considerable loss of blood in addition to plasma.

Total protein, determined by the falling drop method, ranged from 5 to 7 grams, which was approximately 68 to 80 per cent of the corresponding levels in blood serum. The high protein content of the fluid probably: explains the lack of signifi- cant change in serum protein despite marked hemoconcentration. In dogs with tourniquet shock, protein levels of the extravasated fluids have been reported at slightly less (12) than or approximately the same as in blood plasma (21). Similar results are given for the edema fluid in mild trauma (22), traumatic shock (23), burns (24), and in experimental freezing shock $(25,26)$.

Protein fractionation was not done in this study. However, Ricca and co-workers (23) stated that the albumin to globulin ratios of edema fluid from dogs dead of traumatic shock were higher than the corresponding ratios in serum. This was due to increase in albumin or decrease in globulin, or both. The authors calculated that much more protein, especially albumin, was present than could be accounted for by the loss from blood stream, and suggested that the extra amount originates as a result of local liberation of cell proteins from crushed muscle fibers. On the other hand, Ashworth, Jester and Guy (12) working with dogs in shock due to tourniquet and trauma, reported that the amount of protein lost locally was only slightly in excess of the decrease in plasma protein, i.e., loss in the leg amounted to 34.2 per cent of the original circulating protein, while the loss from plasma was 32 per cent of the control value.

Hemoconcentration was a uniform observation in our experiments. Although poor correlation has been reported $(27,16)$ we obtained fairly constant changes in relation to magnitude of edema. Hematocrit levels rose sharply during the first 15 minutes following release of tourniquet, corresponding to the period of greatest fluid loss, less rapidly during the next 15 minutes, and leveled off somewhat abruptly thereafter. In the $\mathrm{dog}$, aside from fluid loss, the initial rapid rise may be due partly to contraction of the spleen $(21,16)$ but whether this holds for the rat, whose splenic framework lacks a significant amount of smooth muscle, is uncertain. Cutaneous vasoconstriction is probably a contributing factor in the rat. In 65 rats the average hematocrit at death was 70 , an increase of 25 points over the mean normal level. Terminally, the blood was dark, viscid, and only a very small amount, i.e., about $1 \mathrm{ml}$. or less, could be obtained by decapitation.

In addition to capillary injury, interruption of 
blood flow to an extremity for 5 hours leads to marked tissue breakdown, especially of muscle. Chemical decomposition, for example, is shown by rise in serum creatine on resumption of circulation. Bollman and Flock (28) found that total anoxemia of muscle for more than 3 hours resulted in almost complete and irreversible hydrolysis of phosphocreatine. When circulation was restored, resynthesis of organic compounds did not occur, and both creatine and inorganic phosphates were rapidly washed out by the blood. In our study, serum creatine levels 30 minutes after tourniquet release were increased approximately 100 per cent over the normal values, and 5 to 6 hours after release the increase was about 400 per cent. In 8 dogs with traumatic shock Duncan and Blalock (29) found that the plasma creatine levels 4 to 6 hours after trauma were considerably elevated in 3 animals, and slightly elevated in 5 animals.

Progressive degeneration of muscle was apparent from microscopic sections made at intervals after renewal of blood flow. There were disruption and fragmentation of fibers, separation into longitudinal fibrils, loss of transverse striations, and areas of granular degeneration. Some fibers were deeply acidophilic or basophilic, while others showed pale staining foci. Nuclear alteration included pyknosis and lysis. Changes were sometimes evident as early as 15 minutes after circulation was restored, and were well developed 2 or 3 hours later. In rats dead from 12 to 20 hours after removal of tourniquet, some muscle fibers showed hyaline necrosis.

Autopsies on control rats which died in shock revealed marked hyperemia of the mesenteric veins. Most organs were dark red, hyperemic and not excessively moist. No free fluid was found in the serous cavities. Microscopically there was generalized hyperemia of viscera involving capillaries and venules. Capillary hemorrhage was rare and usually absent. Focal necrosis and significant cellular exudate were not observed. There was no evidence of widespread tissue edema and pulmonary edema was notably absent.

Parenchymal organs such as liver, adrenal and kidney (especially the first), showed alterations in morphology of the epithelial cells. These were usually reduced in size, irregular in shape, and sometimes appeared shrunken. Cytoplasm was condensed, more deeply acidophilic, homogeneous, and revealed loss of the normal foamy or granular appearance. Nuclei were often smaller than usual, and pyknotic. In the liver, such changes were commonly diffuse, although somewhat more distinct in the central zones of the lobules. While the significance of this lesion is uncertain, it may be related to the loss of intracellular fluid and other components in shock.

Autopsy studies of rats sacrificed at various time intervals after tourniquet removal indicated progressive development of the lesions observed in the control animals. As a result, it was generally possible to distinguish between rats sacrificed 15 or 30 minutes after release of constriction and those sacrificed at the end of 2 or 3 hours.

In these experiments, the magnitude and rapidity of local fluid loss are sufficient per se to explain the development of shock. Experimentally, comparable loss of blood (30 to 32 ) or plasma $(33,34)$ to the exterior results in shock. In the rat, shock is produced by withdrawal of whole blood corresponding in amount and rate to fluid loss by tourniquet (35). From the standpoint of circulatory dynamics, the large extravasation of fluid from the blood stream into the tissues of the hind limb leads to decrease in circulating blood volume, followed by diminished venous return to the heart, reduction in cardiac output and fall in blood pressure (36 to 39 ). Actual determinations have shown that the reduction in blood volume which accompanies both tourniquet and traumatic shock can be accounted for entirely by the quantity of fluid lost in the injured area (40, $17,12)$. The bulk of evidence now favors the view, that, in these forms of shock, increased capillary permeability and loss of fluid are local rather than widespread $(41,40,34)$.

Although there is convincing evidence that shock is initiated by local fluid loss, secondary or sustaining factors undoubtedly play a rôle in its maintenance. These apparently arise in connection with the metabolic disorders resulting from prolonged tissue anoxia. Recent studies $(42,43)$ indicate that a humoral vasodepressor principle originating in liver and skeletal muscle occurs in the blood in the later stage of shock. Such depressor material tends to eliminate compensatory peripheral vascular mechanisms in 
shock, and hence may be a significant factor in the development of irreversibility.

\section{CONCLUSIONS}

1. Fatal tourniquet shock in the rat is associated with marked extravasation of fluid into the injured hind limb.

2. The fluid loss amounts to 2.1 per cent of body weight 15 minutes after tourniquet release, and to $2.8,3.4$ and 4.2 per cent of body weight 30 minutes, 1 hour and 2 hours respectively after release.

3. The magnitude and rapidity of the fluid loss adequately explain the origin of shock. Withdrawal of whole blood in comparable amount and at the same rate results in shock.

4. The development of shock is accompanied by marked hemoconcentration and rise in serum creatine. There is no significant change in total serum protein.

5. Morphologic study of rats dead of tourniquet shock reveals generalized hyperemia of viscera involving capillaries and venules. Capillary hemorrhages are rare and widespread tissue edema does not occur.

\section{BIBLIOGRAPHY}

1. Blalock, A., Experimental shock. The cause of the low blood pressure produced by muscle injury. Arch. Surg., 1930, 20, 959.

2. Hechter, O., Krohn, L., and Harris, J., Rôle of adrenals in production of traumatic shock in rats. Endocrinology, 1942, 31, 439.

3. Van Allen, C. M., An hematocrit method. J. Lab. and Clin. Med., 1925, 10, 1027.

4. Barbour, H. G., and Hamilton, W. F., The falling drop method for determining specific gravity. J. Biol. Chem., 1926, 69, 625.

5. Peters, J. H., The determination of creatinine and creatine in blood and urine with the photoelectric colorimeter. J. Biol. Chem., 1942, 146, 179.

6. Cannon, W. B., and Bayliss, W. M., Report of Shock Committee, Medical Research Committee, No. 26, March, 1919.

7. Parsons, E., and Phemister, D. B., Hemorrhage and "shock" in traumatized limbs; experimental study. Surg. Gynec. Obst., 1930, 51, 196.

8. Cullen, M. L., and Freeman, N. E., Technique for measurement of local fluid loss in experimental traumatic shock. Surgery, 1941, 10, 770.

9. Moon, V. H., Shock and Related Capillary Phenomena. New York, Oxford University Press, 1938.

10. Holt, R. L., and MacDonald, A. D., Observations on experimental shock. Brit. M. J., 1934, 1, 1070.
11. Wilson, H., and Roome, N. W., Effects of constriction and release of an extremity. Proc. Soc. Exper. Biol. and Med., 1934, 32, 261.

12. Ashworth, C. T., Jester, A. W., and Guy, E. L., Local loss of fluid and protein in experimental shock; relation to decrease of plasma volume and total circulating protein. Am. J. Physiol., 1944, 141, 571.

13. Perlow, S., Killian, S. T., Katz, L. N., and Asher, R., Shock following venous occlusion of a leg. Am. J. Physiol., 1941, 134, 755.

14. Shleser, I. H., and Asher, R., Efficacy of adrenal cortical extract and of paredrine in the prevention of experimental shock following venous occlusion of a limb. Am. J. Physiol., 1942, 138, 1.

15. Manery, J. F., and Solandt, D. Y., Studies in experimental traumatic shock with particular reference to plasma potassium changes. Am. J. Physiol., 1943, 138, 499.

16. Green, H. D., Dworkin, R. M., Antos, R. J., and Bergeron, G. A., Ischemic compression shock, with an analysis of local fluid loss. Am. J. Physiol., 1944, 142, 494.

17. Nickerson, J. L., Local fluid loss in trauma. Am. J. Physiol., 1945, 144, 429.

18. Haist, R. E., and Hamilton, J. I., Reversability of carbohydrate and other changes in rats shocked by clamping technique. J. Physiol., 1944, 102, 471.

19. Krogh, A., Anatomy and Physiology of the Capillaries. New Haven, Yale University Press, 1929.

20. Landis, E. M., Capillary pressure and capillary permeability. Physiol. Rev., 1934, 14, 404.

21. Taylor, R. D., and Page, I. H., Mechanism of erythremia. Erythremia resulting from traumatic shock in dogs and from injections of epinephrine into human beings and dogs. Arch. Surg., 1943, 47, 59.

22. Swingle, W. W., Remington, J. W., Kleinberg, W., Drill, V. A., and Eversole, W. J., An experimental study of the tourniquet as a method for inducing circulatory failure in the dog. Am. J. Physiol., 1942, 138, 156.

23. Ricca, R. A., Fink, K., Steadman, L. T., and Warren, S. L., Distribution of body fluids of dogs in traumatic shock. J. Clin. Invest., 1945, 24, 140.

24. Beard, J. W., and Blalock, A., Experimental shock. VIII. The composition of the fluid that escapes from the blood stream after mild trauma to an extremity, after trauma to the intestines, and after burns. Arch. Surg., 1931, 22, 617.

25. Harkins, H. N., and Hudson, J. E., Shock due to freezing: II. Composition of edema fluid. Proc. Soc. Exper. Biol. and Med., 1934, 32, 434.

26. Muirhead, E. E., Ashworth, C. T., Kregel, L. A., and Hill, J. M., Experimental freezing shock. Changes in body fluids and tissues. Arch. Surg., 1942, 45, 863.

27. Shipley, E. G., Meyer, R. K., and McShan, W. H., Shock produced by the application of tourniquets to the hind limbs of rats. Proc. Soc. Exper. Biol. and Med., 1945, 60, 340. 
28. Bollman, J. L., and Flock, E. V., Phosphates in muscle during shock. Proc. Central Soc. Clin. Research, 1944, 17, 62.

29. Duncan, G. W., and Blalock, A., The uniform production of experimental shock by crush injury; possible relationship to clinical crush syndrome. Ann. Surg., 1942, 115, 684.

30. Johnson, G. S., and Blalock, A., Experimental shock. IX. A study of the effects of the loss of whole blood, of blood plasma, and of red blood cells. Arch. Surg., 1931, 22, 626.

31. Freedlander, S. O., and Lenhart, C. H., Traumatic shock. Arch. Surg., 1932, 25, 693.

32. Zweifach, B. W., Lowenstein, B. E., and Chambers, R., Responses of blood capillaries to acute hemorrhage in the rat. Am. J. Physiol., 1944, 142, 80.

33. Harkins, H. N., and Harmon, P. H., Blood concentration produced by plasmapheresis. Surgery, 1937, 1, 276.

34. Price, P. B., Metcalf, W., Longmire, W. P., Hanlon, C. R. and Rizzoli, H. V., Experimental shock. II. Effects of acute plasmapheresis in healthy dogs. Bull. Johns Hopkins Hosp., 1944, 75, 14.

35. Unpublished observations of the authors.
36. McDowall, R. J. S., The circulation in relation to shock. Brit. M. J., 1940, 1, 919.

37. Blalock, A., Principles of Surgical Care. Shock and Other Problems. St. Louis, the C. V. Mosby Co., 1940.

38. Wiggers, C. J., The present status of the shock problem. Physiol. Rev., 1942, 22, 74.

39. Richards, D. W., Circulation in traumatic shock in man; Harvey Lecture, Feb. 17, 1944. Bull New York Acad. Med., 1944, 20, 363.

40. Fine, J., and Seligman, A. M., Traumatic shock; study of problem of "lost plasma" in hemorrhagic, tourniquet, and burn shock by use of radioactive iodoplasma protein. J. Clin. Invest., 1944, 23, 720.

41. Engel, D., and Forrai, E., Capillary permeability in traumatic shock. J. Physiol., 1943, 102, 127.

42. Zweifach, B. W., Abell, R. G., Chambers, R., and Clowes, G. H. A., Rôle of the decompensatory reactions of peripheral blood vessels in tourniquet shock. Surg., Gynec., and Obst., 1945, 80, 593.

43. Shorr, E., Zweifach, B. W., and Furchgott, R. F., On the occurrence, sites, and modes of origin and destruction, of principles affecting the compensatory vascular mechanisms in experimental shock. Science, 1945, 102, 489. 